\title{
Mudas de tamarindeiro produzidas em substratos compostos por bagana de carnaúba e casca de arroz
}

A busca por alternativas para cultivo de espécies frutíferas torna-se cada vez mais oportuno, a fim de reduzir custos utilizando materiais que forneçam condiçõe nutricionais para seu crescimento. Nesse sentido, objetivou-se avaliar a produção de mudas em substratos a base de bagana de carnaúba e casca de arroz em diferentes proporções. O experimento foi realizado em casa de vegetação, entre dezembro de 2018 e fevereiro de 2019 com controle de $70 \%$ de luminosidade. Adotou-se o delineamento inteiramente casualizado (DIC), contendo 6 repetições, distribuído em esquema fatorial $2 \times 3$, referente a dois substratos e três proporções $0 \%, 50 \%$ e $100 \%$ acrescidas de solo para os respectivos substratos, com 6 tratamentos, totalizando 180 mudas experimentais. Aos 60 dias foram analisadas as variáveis: número de folhas, altura da planta, diâmetro do caule, comprimento radicular, volume radicular, massa fresca da parte aérea e do sistema radicular, massa seca da parte aérea e do sistema radicular e índice de qualidade de Dickson. As médias foram comparadas pelo teste Tukey a nível de $5 \%$ de probabilidade. Os melhores resultados foram obtidos sob a testemunha e o uso da bagana de carnaúba em interação a proporção $50 \%$. Sendo assim, a produção de mudas de tamarindeiro é viável tanto em solo quanto em substrato bagana de carnaúba sob a proporção $50 \%$.

\section{Tamarind seedlings produced on substrates composed of carnauba bagana and rice husk}

\begin{abstract}
The search for alternatives to cultivate fruit species is becoming increasingly opportune in order to reduce costs using materials that provide nutritional conditions for their growth. In this sense, the objective was to evaluate the production of seedlings in substrates based on carnauba bagana and rice husk in different proportions. The experiment was carried out in a greenhouse between December 2018 and February 2019 with $70 \%$ light control. It was adopted a completely randomized design (DIC), containing 6 replications, distributed in a $2 \times 3$ factorial scheme, referring to two substrates and three proportions $0 \%, 50 \%$ and $100 \%$ plus soil for the respective substrates, with 6 treatments, totaling 180 experimental seedlings. At 60 days, the following variables were analyzed: number of leaves, plant height, stem diameter, root length, root volume, fresh mass of shoot and root system, dry mass of shoot and root system and quality of life index. Dickson Means were compared by Tukey test at $5 \%$ probability level. The best results were obtained under the control and the use of carnauba bagana in $50 \%$ interaction. Therefore, the production of tamarind seedlings is viable in soil and carnauba bagana substrate under the proportion $50 \%$.
\end{abstract}

Keywords: Organic fertilization; East of maranhense; Tamarindus indica L.

Topic: Uso Sustentável da Biodiversidade

Reviewed anonymously in the process of blind peer.
Received: 04/09/2020

Approved: 08/11/2020
Gessiane Maria da Silva Santos (iD) Universidade Federal do Maranhão, Brasil http://lattes.cnpq.br/9166609911720441 http://orcid.org/0000-0003-3964-1916 gessiane1106@gmail.com

Jéssica Maria de Sousa Oliveira (iD Universidade Federal do Maranhão, Brasil http://lattes.cnpq.br/8949305101190473 http://orcid.org/0000-0002-8031-0636 ihessicasousa01@gmail.com

Joseane Barbosa Araújo Universidade Federal do Maranhão, Brasil http://lattes.cnpq.br/9292120632074841 http://orcid.org/0000-0003-2910-9352 joseane_araujo12@yahoo.com

\section{Vanessa Reis Cardoso (D) \\ Universidade Federal do Maranhão, Brasil http://lattes.cnpq.br/8199995262480877 http://orcid.org/0000-0001-9696-8507 vanessarcardos@gmail.com}

Brenda Ellen Lima Rodrigues (ic

Universidade Federal do Maranhão, Brasil http://lattes.cnpq.br/3744642411826282 http://orcid.org/0000-0001-7542-3030 brendaeld15@gmail.com

Paula Sara Teixeira de Oliveira Universidade Federal do Maranhão, Brasil http://lattes.cnpq.br/3559574180065279 http://orcid.org/0000-0001-8968-7061 paulasara1997@gmail.com

\begin{abstract}
Janaiane Ferreira dos Santos (iD
Universidade Federal do Maranhão, Brasil http://lattes.cnpq.br/9678500549107690 http://orcid.org/0000-0003-0152-5725 janaianeferreira@gmail.com
\end{abstract}

Maria do Livramento da Silva Santos (iD Universidade Federal do Maranhão, Brasil http://lattes.cnpq.br/7505479330022713 http://orcid.org/0000-0002-1273-6889 marialsantos99@outlook.com

Raissa Rachel Salustriano da Silva Matos (it) Universidade Federal do Maranhão, Brasil http://lattes.cnpq.br/0720581765268326 http://orcid.org/0000-0002-8908-2297

raissasalustriano@yahoo.com.br

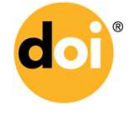

DOI: 10.6008/CBPC2318-2881.2020.004.0005
Referencing this:

SANTOS, G. M. S.; OLIVEIRA, J. M. S.; ARAÚJO, J. B.; CARDOSO, V. R.; RODRIGUES, B. E. L.; OLIVEIRA, P. S. T.; SANTOS, J. F.; SANTOS, M. L. S.; MATOS, R. R. S. S.. Mudas de tamarindeiro produzidas em substratos compostos por bagana de carnaúba e casca de arroz. Nature and Conservation, v.13, n.4, p.37-44, 2020. DOI: http://doi.org/10.6008/CBPC2318-2881.2020.004.0005 


\section{INTRODUÇÃO}

O tamarindo (Tamarindus indica L.) é uma cultura perene pertencente à família das Fabaceae, adaptada à climas tropicais e subtropicais (SOUSA et al., 2010). É muito cultivado no Brasil principalmente na região Nordeste e possui grande importância econômica sendo considerada uma árvore multiuso (FERREIRA et al., 2008).

O elevado custo de produção de mudas frutíferas é atualmente considerado um dos maiores entraves em viveiros, especialmente com insumos e mão-de-obra, sendo o fornecimento adequado de nutrientes um dos principais fatores para o sucesso no desenvolvimento das mudas, contribuindo efetivamente para acelerar seu crescimento e diminuir os custos de produção (MENDONÇA et al., 2008).

Nesse contexto, torna-se necessário a busca por alternativas para reduzir custos sem comprometer a qualidade das espécies. Portanto, substratos alternativos podem ser testados quanto ao potencial de utilização na formação de mudas, bem como em associação com materiais comerciais e não comerciais como bagana de carnaúba e casca de arroz, com objetivo de melhorar a textura e proporcionar condição física e química adequada ao desenvolvimento das mudas (LANGE et al., 2014), tendo em vista bons resultados obtidos na cultura do tomateiro (SILVA JÚNIOR et al., 2014), tamboril (SOUSA et al., 2016).

A utilização de substratos orgânicos na produção de mudas de frutíferas propicia grandes benefícios ao setor agrícola, promovendo melhoria das características químicas, físicas e biológicas do solo proporcionando ambiente favorável ao desenvolvimento das culturas (SÁ et al., 2013). Além de reduzir o descarte ao ar livre e consequentemente o acúmulo dos resíduos no meio ambiente (SILVA JÚNIOR et al., 2014). Outro ponto a ser destacado é a combinação dos substratos em adição a outros materiais. Rodrigues (2012) apontam que para a produção de mudas de boa qualidade deve-se levar em conta a combinação de substratos bem como a proporção. Várias formulações de substratos orgânicos e inorgânicos são utilizadas na produção de mudas, no entanto, é necessário determinar o mais apropriado para cada espécie, de modo a atender a demanda por nutrientes (ALMEIDA et al., 2012). Diante do exposto, a presente pesquisa teve como objetivo avaliar a produção de mudas de tamarindeiro com substratos compostos por bagana de carnaúba e casca de arroz sob diferentes proporções.

\section{MATERIAIS E MÉTODOS}

O experimento foi realizado em casa de vegetação com controle de luminosidade a $70 \%$, no período de dezembro de 2018 a fevereiro de 2019, no Centro de Ciências Agrárias e Ambientais (CCAA) da Universidade Federal do Maranhão (UFMA) no município de Chapadinha/MA (03ㅇ4'17" S e 43 20'29" W e altitude de 107 m). O clima da região é classificado como Aw tropical úmido, com precipitação média anual de $1613 \mathrm{~mm}$ e temperatura anual média superior a 27으 (PASSOS et al., 2016).

Para a produção das mudas de tamarindeiro foi adotado o delineamento inteiramente casualizado com tratamentos distribuídos em esquema fatorial $2 \times 3$, referente a dois substratos, bagana de carnaúba (BC) e casca de arroz (CA) e três proporções, 0\%(solo Latossolo Amarelo distrófico) 50\% e 100\% acrescidas 
de solo para ambos os substratos, com seis repetições e cinco mudas por repetição, totalizando assim 180 mudas de tamarindeiro.

Foi realizada análise granulométrica do solo utilizado para formulação dos substratos verificando-se

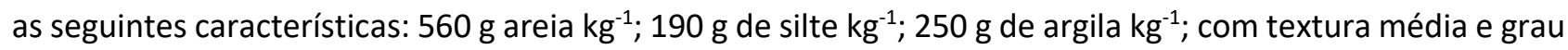
de floculação de $77 \mathrm{~g}$ sendo classificado como Latossolo Amarelo distrófico (SANTOS et al., 2018). A bagana de carnaúba proveniente da região de Vargem grande, MA foi triturada em picador de forragem e peneirada posteriormente em peneira com malha de $5 \mathrm{~mm}$ a fim de facilitar a homogeneização do substrato. A casca de arroz foi adquirida de agroindústrias de Chapadinha/MA após o beneficiamento da cultura.

Os sacos de polietileno na dimensão de $12 \times 20 \mathrm{~cm}$ foram preenchidos com as proporções dos respectivos tratamentos, sendo semeadas duas sementes por recipiente. A irrigação prosseguiu diariamente de acordo com a necessidade da cultura com regador manual com capacidade de 5 L. Aos 28 dias após a semeadura realizou-se o desbaste, deixando apenas a muda mais vigorosa para posterior avaliação.

As sementes foram extraídas manualmente de frutos oriundos de matrizes da região de Petrolina PE sendo embebidos em água por um período de 48 horas para quebrar a dormência e ainda facilitar a extração das sementes. A caracterização química do substrato bagana de carnaúba foi realizada no Laboratório de Ciências do Solo da Universidade Federal do Ceará, Fortaleza - CE, sendo analisados: pH, matéria orgânica, teores de nitrogênio, fósforo, potássio, cálcio, magnésio e enxofre (Tabela 1).

Tabela 1: Valores de $\mathrm{pH}$, matéria orgânica (M.O) e teores de nitrogênio $(\mathrm{N})$, fósforo $(\mathrm{P})$, potássio (K), cálcio (Ca), magnésio (Mg) e enxofre (S).

\begin{tabular}{|c|c|c|c|c|c|c|c|c|}
\hline \multirow{2}{*}{ Substratos } & \multirow[t]{2}{*}{$\mathrm{pH}$} & \multirow{2}{*}{$\begin{array}{l}\mathrm{MO} \\
\text { g.kg-1 }\end{array}$} & \multirow{2}{*}{$\begin{array}{l}\mathrm{N} \\
\text { g.kg-1 }\end{array}$} & \multirow{2}{*}{$\begin{array}{l}\mathrm{P} \\
\mathrm{mg} \cdot \mathrm{kg}^{-1}\end{array}$} & $\mathrm{~K}$ & $\mathrm{Ca}$ & $\mathrm{Mg}$ & $\mathrm{S}$ \\
\hline & & & & & \multicolumn{2}{|c|}{$\mathrm{cmol}_{\mathrm{c}} \mathrm{kg}^{-1}$} & \multicolumn{2}{|c|}{$\mathrm{cmol}_{\mathrm{c}} \mathrm{kg}^{-1}$} \\
\hline $0 \% \mathrm{BC}$ & 4 & 22,8 & 1,14 & 3,5 & 0,14 & 0,69 & 0,53 & 2,82 \\
\hline $50 \%$ BC & 5 & 51,47 & 3,56 & 17 & 0,46 & 4,1 & 1,6 & 6,3 \\
\hline $100 \% \mathrm{BC}$ & 5,3 & 598,86 & 4,02 & 89 & 3,88 & 19,8 & 10,4 & 34,6 \\
\hline
\end{tabular}

Aos 60 dias após a semeadura (DAS) avaliou-se o efeito dos tratamentos sobre as mudas de tamarindeiro através da determinação do número de folhas realizada pela contagem de folhas das plântulas, a altura da planta determinada acima do nível do solo até o ápice da plântula com auxílio de régua milimetrada, diâmetro do caule obtido com paquímetro digital, comprimento radicular obtido por meio de régua milimetrada, volume radicular realizado por meio do deslocamento de coluna de água em proveta graduada, massa fresca da parte aérea e sistema radicular pesada em balança com 0,01g de precisão, massa seca da parte aérea e sistema radicular com material vegetal conduzido a estufa com circulação de ar forçado à temperatura de 65 으 por período de 72 horas e pesada em balança com $0,01 \mathrm{~g}$ de precisão.

Determinou-se ainda o índice de qualidade de Dickson (IQD), por meio da fórmula descrita por Dickson et al. (1960), como demonstra a equação:

$$
\mathrm{IQD}=\frac{\mathrm{MST}(\mathrm{g})}{\mathrm{AP}(\mathrm{cm}) / \mathrm{DC}(\mathrm{mm})+\operatorname{MSPA}(\mathrm{g}) / \operatorname{MSSR}(\mathrm{g})}
$$


MSPA: massa seca da parte aérea; MSSR: massa seca do sistema radicular.

Os dados foram analisados e interpretados a partir da análise de variância (ANOVA) e as médias comparadas entre si pelo teste Tukey ao nível de 5\% de probabilidade por meio do programa estatístico Infostat ${ }^{\circledast}$ (DI RIENZO et al., 2011).

\section{RESULTADOS E DISCUSSÃO}

Observa-se na análise de variância (Tabela 2) que todas as variáveis analisadas apresentaram efeito significativo para o fator substratos $(S)(p<0,01)$, exceto comprimento radicular $(p<0,05)$. Para as proporções (P) todas as variáveis apresentaram efeito significativo $(p<0,01$ e $p<0,05)$ com exceção do número de folhas que não apresentou efeito significativo. Foi registrada interação significativa para diâmetro do caule, comprimento radicular, massa fresca da parte aérea e sistema radicular, massa seca da parte aérea e sistema radicular, índice de qualidade de Dickson $(p<0,01)$ e volume radicular $(p<0,05)$.

Tabela 2: Resumo da análise de variância para as variáveis número de folhas (NF), altura da planta (AP), diâmetro do caule (DC), comprimento radicular (CR), volume radicular (VR), massa fresca da parte aérea (MFPA), massa fresca do sistema radicular (MFSR), massa seca da parte aérea (MSPA), massa seca do sistema radicular (MSSR) e índice de qualidade de Dickson (IQD) de mudas de tamarindeiro.

\begin{tabular}{llllll}
\hline Fonte de variação & $\mathrm{NF}$ & $\mathrm{AP}$ & $\mathrm{DC}$ & $\mathrm{CR}$ & $\mathrm{VR}$ \\
\cline { 2 - 6 } & $\mathrm{F}$ & $\mathrm{F}$ & $\mathrm{F}$ & $\mathrm{F}$ & $\mathrm{F}$ \\
\hline $\mathrm{S}$ & $57,93^{* *}$ & $30,23^{* *}$ & $57,11^{* *}$ & $0,65^{\text {ns }}$ & $55,73^{* *}$ \\
$\mathrm{P}$ & $2,84^{\mathrm{ns}}$ & $25,77^{* *}$ & $80,15^{* *}$ & $22,29^{* *}$ & $3,48^{*}$ \\
SXP & $3,17^{\text {ns }}$ & $1,46^{\text {ns }}$ & $26,67^{* *}$ & $6,81^{* *}$ & $3,55^{*}$ \\
\hline CV (\%) & 16,57 & 5,13 & 6,57 & 10,97 & 23,01 \\
\hline Fonte de variação & MFPA & MFSR & MSPA & MSSR & IQD \\
S & $160,69^{* *}$ & $65,65^{* *}$ & $78,01^{* *}$ & $48,08^{* *}$ & $63,14^{* *}$ \\
P & $11,01^{* *}$ & $24,66^{* *}$ & $63,59^{* *}$ & $4,69^{*}$ & $20,42^{* *}$ \\
SXP & $10,29^{* *}$ & $9,41^{* *}$ & $9,17^{* *}$ & $8,56^{* *}$ & $11,72^{* *}$ \\
\hline CV (\%) & 14,78 & 26,56 & 13,99 & 22,98 & 19,01 \\
\hline
\end{tabular}

S: substratos; P: proporções; ${ }^{* *}$ : significativo ao nível de $1 \%$ de probabilidade; ${ }^{*}$ : significativo a $5 \%$ de probabilidade; ${ }^{\text {ns }}$ : não significativo pelo teste F; CV: coeficiente de variação.

Efeitos significativos para proporções e interação entres os fatores não foram diagnosticados para o número de folhas, contudo efeitos individuais dos substratos foram verificados, tendo melhores resultados o substrato bagana de carnaúba cuja proporção $50 \%$ (Tabela 3).

Tabela 3: Teste de médias das variáveis número de folhas (NF), altura da planta (AP), diâmetro do caule (DC), comprimento radicular (CR) e volume radicular (VR) das mudas de Tamarindus indica L. em função da bagana de carnaúba $(B C)$ e casca de arroz (CA) sob diferentes proporções.

\begin{tabular}{llllll}
\hline Tratamentos & NF & AP & DC & CR & VR \\
\hline $0 \%$ BC & $5,50 \mathrm{ab}$ & $26,88 \mathrm{ab}$ & $3,30 \mathrm{~b}$ & $24,41 \mathrm{bc}$ & $2,00 \mathrm{bc}$ \\
$50 \% \mathrm{BC}$ & $6,30 \mathrm{a}$ & $28,85 \mathrm{a}$ & $3,74 \mathrm{a}$ & $28,54 \mathrm{~b}$ & $2,73 \mathrm{ab}$ \\
$100 \% \mathrm{BC}$ & $4,80 \mathrm{bc}$ & $25,34 \mathrm{c}$ & $2,88 \mathrm{c}$ & $27,60 \mathrm{bc}$ & $2,87 \mathrm{a}$ \\
$0 \% \mathrm{CA}$ & $3,73 \mathrm{c}$ & $25,45 \mathrm{~b}$ & $3,49 \mathrm{ab}$ & $22,45 \mathrm{c}$ & $1,38 \mathrm{c}$ \\
$50 \% \mathrm{CA}$ & $3,53 \mathrm{c}$ & $26,25 \mathrm{~b}$ & $2,89 \mathrm{c}$ & $34,54 \mathrm{a}$ & $1,57 \mathrm{c}$ \\
$100 \% \mathrm{CA}$ & $3,57 \mathrm{c}$ & $22,09 \mathrm{c}$ & $2,03 \mathrm{~d}$ & $25,96 \mathrm{bc}$ & $1,27 \mathrm{c}$ \\
\hline DMS & 1,33044 & 2,32636 & 0,35288 & 5,25031 & 0,79585 \\
\hline
\end{tabular}

Médias seguidas de letras iguais não diferem entre si ao nível de $5 \%$ de probabilidade.

Brito et al. (2017) ao reutilizar resíduos regionais como substratos na produção de mudas de cultivares de alface a partir de sementes com e sem peletização obtiveram maior número de folhas no 
substrato resíduo de carnaúba + casca de arroz diferindo estatisticamente do substrato resíduo de carnaúba semidecomposta.

A superioridade da bagana de carnaúba deve-se ao fato deste material possuir maior aporte de nutriente em relação à casca de arroz, pelo fornecimento do nitrogênio que está intimamente relacionado ao crescimento vegetativo das plantas que conforme relatado no estudo realizado por Sousa et al. (2016) esta informação foi evidente ao analisar as características da casca de arroz e bagana de carnaúba.

A altura da planta apresentou resultados semelhante ao número de folhas, na qual, a maior altura resultou na utilização do substrato bagana de carnaúba sob a proporção 50\% (Tabela 3). Paiva et al. (2011) ressaltam que substratos de fontes orgânicas decompostas apresentam maior retenção de umidade e, por conseguinte, maior fornecimento de nutrientes que possibilitam o favorecendo do crescimento de mudas.

Silva Júnior et al. (2014) estudando o aproveitamento de materiais alternativos na produção de mudas de tomateiro, verificaram que resíduo de carnaúba + casca de arroz e bagana de carnaúba semidecomposta resultaram em maiores alturas de plantas, que podem ainda estar associado ao incremento de nutrientes fornecidos pelos resíduos agroindustriais por possuírem teores de cálcio e fósforo elementos que proporcionam incremento na altura das plantas (SARAIVA et al., 2011).

Quanto ao diâmetro do caule foram encontrados efeitos positivos no substrato BC onde maiores diâmetros foram obtidos na proporção 50\% BC (Tabela 3) e à medida que se adicionou a casca de arroz houve uma redução no diâmetro do caule. Santos (2018) avaliando diferentes substratos na cultura do tamarindeiro obtiveram melhores diâmetro na proporção 1:1:1 (solo + areia + composto orgânico). Entretanto, substratos com composto orgânico conseguem reter mais nutrientes e são menos suscetíveis à perda dos mesmos por lixiviação, o que acaba propiciando melhores respostas do vegetal, como altura e diâmetro do caule (PAIVA et al., 2011).

Contudo, houve interação entre os substratos e as diferentes proporções para o diâmetro do caule, corroborando com os resultados obtidos por Sousa et al. (2016), que também verificaram interação para diâmetro do caule ao testar diferentes fontes de resíduos orgânicos incluindo bagana de carnaúba e casca de arroz em proporções de solo em mudas de tamboril.

As mudas produzidas na proporção $100 \%$ BC não tiveram bom desenvolvimento conforme indica a Tabela 1, esta proporção apresenta alto teor de potássio que apesar deste promover maior engrossamento do caule (VALERI et al., 2005) para a cultura este teve efeito inibidor. Estes resultados, são semelhantes aos obtidos por Delarmelina et al. (2014) que avaliando diferentes substratos para a produção de Sesbania virgata obtiveram maiores médias de diâmetro do caule em tratamentos com teores baixos de potássio.

Para a variável comprimento radicular, efeitos individuais para os substratos não foram verificados, contudo, houve interação entre os fatores, destacando com maiores resultados a proporção $50 \%$ casca de arroz, contrapondo os dados das demais variáveis que obtiveram maiores efeitos com substrato bagana de carnaúba. Mendes et al., (2018) ao estudar o efeito de diferentes substratos e ambientes na emergência e no desenvolvimento inicial do açaizeiro também não teve efeitos significativos no crescimento radicular ao 
utilizar bagana de carnaúba se destacando os húmus de minhoca o melhor para esta variável.

Segundo Steffen et al. (2010) a casca de arroz uma vez misturada a outros materiais, possibilita uma boa drenagem e oxigenação para as raízes proporcionando bom desenvolvimento radicular, que conforme ressaltam Lima et al. (2006) a aeração dos substratos é um dos fatores mais envolvidos no crescimento das raízes. Quanto ao volume radicular (diferente da casca de arroz), os aumentos da proporção de bagana de carnaúba ocasionaram efeitos significativos nas mudas de tamarindeiro, na qual, a proporção $100 \%$ favoreceu o melhor incremento para esta variável, sendo superior aos resultados obtidos no substrato casca de arroz (Tabela 3).

A resposta do volume radicular em relação à maior proporção bagana de carnaúba, pode ser explicado por este substrato apresentar espaço poroso, proporcionando diferentes espaços de aeração ao desenvolvimento radicular como relatado por Silva Júnior et al. (2014) que substratos com menor espaço poroso aferiram valores de volume radicular bem abaixo e ao utilizar bagana de carnaúba + casca de arroz obtiveram resultados superiores aos demais.

Quanto a massa fresca da parte aérea (Tabela 4), as proporções para os substratos bagana de carnaúba não diferiram da testemunha, no entanto, a proporção $50 \%$ BC acrescida de solo promoveu maior fitomassa para as mudas de tamarindeiro, havendo redução à medida que aumentou as proporções de casca de arroz. Segundo Cruz et al. (2010) esta variável é importante por fornecer maior vigor e capacidade fotossintética, levando ao melhor desenvolvimento da planta.

Tabela 4: Teste de médias das variáveis massa fresca da parte aérea (MFPA), massa fresca do sistema radicular (MFSR), massa seca da parte aérea (MSPA), massa seca do sistema radicular (MSSR) e índice de qualidade de Dickson (IQD) das mudas de Tamarindus indica L. em função da bagana de carnaúba (BC) e casca de arroz (CA) sob diferentes proporções.

\begin{tabular}{llllll}
\hline Tratamentos & MFPA & MFSR & MSPA & MSSR & IQD \\
\hline $0 \% \mathrm{BC}$ & $3,06 \mathrm{a}$ & $1,22 \mathrm{c}$ & $1,42 \mathrm{a}$ & $0,61 \mathrm{ab}$ & $0,19 \mathrm{a}$ \\
$50 \% \mathrm{BC}$ & $3,63 \mathrm{a}$ & $2,13 \mathrm{~b}$ & $1,36 \mathrm{a}$ & $0,80 \mathrm{a}$ & $0,23 \mathrm{a}$ \\
$100 \% \mathrm{BC}$ & $3,07 \mathrm{a}$ & $3,18 \mathrm{a}$ & $1,01 \mathrm{~b}$ & $0,80 \mathrm{a}$ & $0,18 \mathrm{ab}$ \\
$0 \% \mathrm{CA}$ & $2,29 \mathrm{~b}$ & $0,86 \mathrm{c}$ & $1,27 \mathrm{a}$ & $0,49 \mathrm{~b}$ & $0,18 \mathrm{ab}$ \\
$50 \% \mathrm{CA}$ & $1,75 \mathrm{~b}$ & $0,90 \mathrm{c}$ & $0,88 \mathrm{~b}$ & $0,56 \mathrm{~b}$ & $0,13 \mathrm{~b}$ \\
$100 \% \mathrm{CA}$ & $1,07 \mathrm{c}$ & $1,32 \mathrm{c}$ & $0,35 \mathrm{c}$ & $0,24 \mathrm{c}$ & $0,05 \mathrm{c}$ \\
\hline DMS & 0,64357 & 0,74773 & 0,25781 & 0,23570 & 0,05363 \\
\hline
\end{tabular}

Médias seguidas de letras iguais não diferem entre si ao nível de $5 \%$ de probabilidade.

Para a massa fresca do sistema radicular a proporção $100 \%$ BC se sobressaiu diferindo-se das demais, não havendo efeitos significativos nos tratamentos constituídos de casca de arroz. Os resultados expressivos para esta variável, deve-se ao maior teor de nutrientes como nitrogênio presentes na bagana de carnaúba, corroborando com o estudo realizado por Vogado et al. (2015) que ao utilizar o substrato resíduo de carnaúba e casca de arroz obtiveram aumento linear da massa fresca da raiz.

Quanto à massa seca da parte aérea, a proporção $0 \%$ e $50 \%$ proporcionaram melhores resultados em interação ao substrato bagana de carnaúba, não havendo significância para as proporções de casca de arroz. Podendo ser explicado por a bagana de carnaúba possibilitar decomposição mais rápida por parte dos microrganismos (SEABRA JÚNIOR et al., 2004) disponibilizando nutrientes mais rapidamente para as mudas, sendo equivalente ao estudo de Veras et al. (2015) que trabalhando com diferentes substratos para 
desenvolvimento de tamarindo, constatou que quando mesclado solo com composto orgânico, esse propiciava melhores valores de crescimento das plantas e maior incremento da massa seca da parte aérea.

Para massa seca do sistema radicular, as proporções crescentes de bagana de carnaúba (50 e 100\%) obtiveram médias iguais, fornecendo melhor incremento para esta variável, ao passo que, para casca de arroz estas proporções obtiveram menores valores. O fornecimento de umidade do solo associado as características físicas da bagana de carnaúba podem ter favorecidos incremento da massa seca radicular. Góes et al. (2011) ao testar diferentes substratos na formação de mudas de tamarindeiro obteve melhores resultados em substratos que continham $50 \%$ solo e $50 \%$ húmus de minhoca para peso seco da raiz.

Para o índice de qualidade de Dickson (Tabela 4), as mudas de tamarindeiro produzidas em substrato casca de arroz obtiveram índice inferior a 0,18 ao passo que as produzidas em bagana de carnaúba aferiram índice superior, contudo, a utilização das proporções $0 \%$ e 50\% favoreceram aumento do índice de qualidades das mudas atingindo 0,23 .

No entanto, tal resultado já era esperado por ser correspondente aos obtidos pelas demais variáveis estudadas neste trabalho, mediante as respostas positivas das mudas de tamarindeiro em função do uso dos substratos bagana de carnaúba e casca de arroz em diferentes proporções. Segundo Fonseca et al. (2002) e Delarmelina et al. (2015) o índice de qualidade de Dickson é um bom indicador da qualidade das mudas, pois para seu cálculo são consideradas as robustezes e o equilíbrio da distribuição da biomassa na muda, ponderando os resultados de vários parâmetros importantes empregados para avaliação da qualidade.

\section{CONCLUSÕES}

A produção de mudas de tamarindeiro é viável tanto em solo quanto em substrato com $50 \%$ de bagana de carnaúba, pois fornecem incrementos iguais, estimulando o desenvolvimento das mudas de tamarindeiro.

\section{REFERÊNCIAS}

ALMEIDA, L. V. B.; MARINHO, C. S.; MUNIZ, R. A.; CARVALHO, A. J. C.. Disponibilidade de nutrientes e crescimento de porta - enxertos de citros fertilizados com fertilizantes convencionais e de liberação lenta. Revista Brasileira de Fruticultura, Jaboticabal, v.34, n.1, p.289-296, 2012. DOI: https://doi.org/10.1590/S0100-29452012000100038

BRITO, L. P. S.; BECKMANN-CAVALCANTE, M. Z.; AMARAL, G. C.; SILVA, A. A.; AVELINO, R. C.. Reutilização de resíduos regionais como substratos na produção de mudas de cultivares de alface a partir de sementes com e sem peletização. Revista de La Facultad de Agronomía, La Plata, v.116, n.1, p.51-61, 2017.

CRUZ, C. A. F.; PAIVA, H. N.; NEVES, J. C. L.; CUNHA, A. C. M. C. M.. Resposta de mudas de Senna macranthera (DC. excollad) H. S. Irwin \& Barnaby (fedegoso) cultivadas em latossolo vermelho - amarelo distrófico a macronutrientes. Revista Árvore, Viçosa, v.34, n.1, p.13-24, 2010. DOI: https://doi.org/10.1590/S0100-67622010000100002

DELARMELINA, W. M.; CALDEIRA, M. V. W.; FARIA, J. C. T.; GONÇALVES, E. O.; ROCHA, R. L. F.. Diferentes substratos na produção de mudas de Sesbania virgata (Cav.) Pers. Floresta e Ambiente, Rio de Janeiro, v.21, n.2, p.224-233, 2014. DOI: https://doi.org/10.4322/floram.2014.027

DELARMELINA, W. M.; CALDEIRA, M. V. W.; FARIA, J. C. T.; GONÇALVES, E. O.; ROCHA, R. L. F.. Uso de resíduo orgânico em substrato para produção de Chamaecrista desvauxii (Collad.) Killip var. latistipula (Benth.). Cerne, Rio de Janeiro, v.21, n.3, p.429-437, 2015. DOI: http://dx.doi.org/10.4322/floram.2014.027

DI RIENZO, J. A.; CASANOVES, F.; BALZARINI, M. G.; GONZALEZ, L.; TABLADA, M.; ROBLEDO, C. W.. Grupo InFostat, Faculdade de Ciências agropecuárias, Universidad Nacional de Córdoba, Argentina. Infostat, 2011.

DICKSON, A.; LEAF, A. L.; HOSNER, J. F.. Quality appraisal of white spruce and white pine seedling stock in nurseries. The Forestry Chronicle, Canadá, v.36, p.10-13, 1960.

FERREIRA, E. A.; MENDONÇA, V.; SOUZA, H. A.; RAMOS, J. D.. Adubação fosfatada e potássica na formação de mudas de Tamarindeiro. Scientia Agrária, Curitiba, v.9, n.4, p.475-480, 
2008.

FONSECA, É. P.; VALÉRI, S. V.; MIGLIORANZA, É.; FONSECA N. A. N.; COUTO, L.. Padrão de qualidade de mudas de Trema micrantha (L.) Blume, produzidas sob diferentes períodos de sombreamento. Revista Árvore, Viçosa, v.26, n.4, p.515-523, 2002. DOI: https://doi.org/10.1590/S010067622002000400015

GÓES, G. B.; MELO, I. G. C.; DANTAS, D. J.; ARAÚJO, W. B. M. ALENCAR, R. D.. Utilização de húmus de minhoca como substrato na produção de mudas de tamarindeiro. Revista Verde de Agroecologia e Desenvolvimento Sustentável, Mossoró, v.6, n.4, p.125-131, 2011.

LANGE, A.; SILVA JUNIOR, J. G.; CAIONE, G.. Substratos para produção de mudas de Schizolobium amazonicum. Revista Tecnologia \& Ciência Agropecuária, João Pessoa, v.8, n.1, p.49-54, 2014.

LIMA, R. L. S.; SEVERINO, L. S.; SILVA, M. I. L.; JERÔNIMO, J. F.; VALE, L. S.; BELTRÃO, N. E. M.. Substratos para produção de mudas de mamoneira compostos por misturas de cinco fontes de matéria orgânica. Ciência e Agroecologia, Lavras, v.30, n.3, p.474-479, 2006. DOI: https://doi.org/10.1590/S1413-70542006000300013

MENDES, N. N. B.; LIMA, DENISE. C.; CORRÊA, MÁRCIO. C. $M$.. Emergência e desenvolvimento inicial do açaizeiro em diferentes substratos e ambiente. Acta Iguazu, Cascavel, v.17, n.2, p.84-96, 2018.

MENDONÇA, V.; ABREU, N. A. A.; SOUZA, H. A.; TEIXEIRA, G. A.; HAFLE, O. M.; RAMOS, J. D.. Diferentes ambientes e Osmocote na produção de mudas de tamarindeiro (Tamarindus indica). Ciência e Agrotecnologia, Lavras, v.32, n.2, p.391-397, 2008.

PAIVA, E. P.; MAIA, S. S. S.; CUNHA, C. S. M.; COELHO, M. F. B.; SILVA, F. N.. Composição do substrato para o desenvolvimento de mudas de manjericão (Ocimum basilicum L.). Revista Caatinga, Mossoró, v.24, n.4, p.62-67, 2011.

PASSOS, M. L. V.; ZAMBRZYCKI, G. C.; PEREIRA, R. S.. Balanço hídrico e classificação climática para uma determinada região de Chapadinha/MA. Revista Brasileira de Agricultura Irrigada, Fortaleza, v.10, n.4, p.758-766, 2016. DOI: http://doi.org/10.7127/rbai.v10n400402

RODRIGUES, M. L.. Mudas de alface (Lactuca sativa L.) produzidas com diferentes substratos orgânicos. In: CONGRESSO NORTE E NORDESTE DE PESQUISA E INOVAÇÃO, 7. Anais. Palmas, 2012.

SÁ, F. V.; BRITO, M. E. B.; MELO, A. S.; ANTÔNIO NETO, P.; FERNANDES, P. D.; FERREIRA, I. B.. Produção de mudas de mamoeiro irrigadas com água salina. Revista Brasileira Engenharia Agrícola Ambiental, Campina Grande, v.17, n.10, p.1047-1054, 2013.

SANTOS, P. L. F.; PAIXÃO, A. P.; SILVA, O. N. M.; CASTILHO, R. M. M.; FARIA, R. C.; VIEIRA, N. C. S.. Doses de adubo de liberação lenta no crescimento inicial de mudas de tamarindo. Nucleus, São Paulo, v.15, n.1, p.137-146, 2018. DOI: http://dx.doi.org/10.3738/1982.2278.2800

SANTOS, H. G.. Sistema Brasileiro de Classificação de solos. 5 ed. Brasília: Embrapa, 2018.

SARAIVA, K. R.; NASCIMENTO, R. S.; SALES, F. A. L.; ARAÚJO, H. F.. Produção de mudas de mamoeiro sob doses de adubação fosfatada utilizando como fonte superfosfato simples. Revista Brasileira de Agricultura Irrigada, Fortaleza, v.5, n.4, p.376-383, 2011.

SEABRA JÚNIOR, S.; GADUN, J.; CARDOSO, A. I. I.. Produção de pepino em função da idade das mudas produzidas em recipientes com diferentes volumes de substrato. Horticultura Brasileira, Brasília, v.22, n.3, p.610- 613, 2004. DOI: https://doi.org/10.1590/S0102-05362004000300022

SILVA JÚNIOR, J. V.; BECKMANN-CAVALCANTE, M. Z.; BRITO, L. P. S.; AVELINO, R. C.; CAVALCANTE, Í. H. L..

Aproveitamento de materiais regionais na produção de mudas de tomateiro sob adubação foliar. Revista Ciência Agronômica, Fortaleza, v.45, n.3, p.528-536, 2014. DOI: http://dx.doi.org/10.1590/S1806-66902014000300013

SOUSA, D. M. M.; BRUNO, R. L. A.; DORNELAS, C. S. M.; ALVES, E. U.; ANDRADE, A. P.; NASCIEMNTO, L. C.. Caracterização morfológica de frutos e sementes e desenvolvimento pós - seminal de Tamarindus indica L. Leguminosae: Caesalpinioideae. Revista Árvore, Viçosa, v.34, n.6, p.1009-1015, 2010. DOI: http://dx.doi.org/10.1590/S0100-67622010000600006

SOUSA, L. B.; LUSTOSA FILHO, J. F.; AMORIM, S. P. N.; NÓBREGA, R. S. A.; NÓBREGA, J. C. A.. Germinação, crescimento e nodulação natural de enterolobium contortisiluqunn em substratos regionais. Revista Brasileira de Agroecologia, Rio de Janeiro, v.11 n.4, p.345-353, 2016.

STEFFEN, G. P. K.; ANTONIOLLI, Z. I.; STEFFEN, R. B. MACHADO, R. G.. Casca de arroz e esterco bovino como substratos para a multiplicação de minhocas e produção de mudas de tomate e alface. Acta Zoológica Mexicana, n.26, p.333-343, 2010

VALERI, S. V.; CORRADINI, L.. Fertilização em viveiros para a produção de mudas de Eucalyptus e Pinus. In: GONÇALVES, J. L. M.; BENEDETTI, V.. Nutrição e fertilização florestal. Piracicaba: Instituto de Pesquisas e Estudos Florestais, 2005 p.167-190.

VERAS, M. L. M.; MELO FILHO, J. S.; ARAÚJO, D. L.; ALVES, L. S.; ANDRADE, R.. Formação de mudas de tamarindo (Tamarindus indica L.) utilizando substratos em função da aplicação de fertilizante orgânico. Revista Terceiro Incluído, São Paulo, v.5, n.2, p.205-218, 2015. DOI: http://dx.doi.org/10.5216/teri.v5i2.3874

VOGADO, R. F.; LIMA, F. N.; AVELINO, R. C.; DANTAS, B. L.; VENDRUSCOLO, J.; FELIX, V. J. L.. Resíduo da carnaubeira utilizado como substrato na produção de mudas de melancia. In: CONGRESSO BRASILEIRO DE CIÊNCIA DO SOLO, 35. Anais. Natal. 2015.

A CBPC - Companhia Brasileira de Produção Científica (CNPJ: 11.221.422/0001-03) detém os direitos materiais desta publicação. Os direitos referem-se à publicação do trabalho em qualquer parte do mundo, incluindo os direitos às renovações, expansões e disseminações da contribuição, bem como outros direitos subsidiários. Todos os trabalhos publicados eletronicamente poderão posteriormente ser publicados em coletâneas impressas sob coordenação da Sustenere Publishing da Companhia Brasileira de Produção Científica e seus parceiros autorizados. Os (as) autores (as) preservam os direitos autorais, mas não têm permissão para a publicação da contribuição em outro meio, impresso ou digital, em português ou em tradução. 